\title{
DESIGN HIGH GAIN DC-DC BOOST CONVERTER WITH COUPLING INDUCTOR AND SIMULATION IN PSIM
}

\author{
Preti Tyagi $^{1}$, V.C. Kotak ${ }^{2}$, V. P. Sunder Singh ${ }^{3}$ \\ ${ }^{1}$ Research Scholar [Etrx.], Dept of Electronics Engg, Shah \&Anchor Kutchhi Engineering College, Mumbai India \\ ${ }^{2}$ Associate Professor, Dept of Electronics Engineering, Shah \&Anchor Kutchhi Engineering College, Mumbai, India \\ ${ }^{3}$ Rtd. Professor, Dept. of Electrical Engineering, Indian Institute of Technology (IIT-Powai), Mumbai, India
}

\begin{abstract}
The high gain DC-DC converter with coupling inductor is design to boost low voltages to voltages into high range of 30 to 50 times input voltage. It is especially useful in boosting low solar panel voltage $(12 \mathrm{~V})$ to high voltage, so that $230 \mathrm{~V}$ ac can be generated. At the time the efficiency is also high and it is cost effective. It is a transformer less topology. This converter will work with input voltage of $12 \mathrm{Vdc}$, and generate constant output voltage of $360 \mathrm{Vdc}$ with the help of PI controller. To achieve high voltage output gain the converter output terminal and boost output terminal are connected in serially with the isolated inductor with less voltage stress on controlled power switch and power diodes. PSIM software has been used for simulation.
\end{abstract}

Keywords: High gain, boost converter, coupling inductor, PI controller.

****

\section{INTRODUCTION}

High boost dc-dc converter operating at high voltage regulation is mainly required in many industrial applications. High gain dc-dc boost converter play a important role in renewable energy sources such as solar energy system, fuel energy system, DC back up energy system of UPS, High intensity discharge lamp and automobile applications.

The rapid increase in the demand for electricity and the recent change in the environmental conditions such as global warming led to a need for a new source of energy that is cheaper and sustainable. Solar energy has offered promising results in the quest of finding the solution to the problem. Therefore, the DC system with multiple DC/DC converters may play an important role in the future power systems and industrial applications In addition, the design of high power DC-DC converters and their Controller plays an important role to control power regulation particularly for a common DC bus.

Basically there are two types of topology dc-dc converter present, one is transformer less topology and other one is with transformer [2]. According to the efficiency the transformer less topology is better than with transformer topology [1].

Theoretically, a dc - dc boost converter can achieve a high step-up voltage gain with an extremely high duty ratio near to $100 \%$. However, in practice, the step up voltage gain is limited due to the effect of power switches, rectifier diode, the equivalent series resistance (ESR) of inductors and capacitors. Many topologies have been presented to provide a high step up voltage gain without an extremely high duty ratio.
However, these types are all complex and have a high cost. The coupled inductor technique provides solution to achieve a high voltage gain, low voltage stress on the active switch, and high efficiency without the penalty of high duty ratio. Thus switching inductor boost type provides high gain and high efficiency.

\section{TOPOLOGY SELECTION}

As we face several problem in the boost converters circuit like high reverse recovery current across the rectifier diode, turn ON and turn OFF losses, the leakage inductance energy (which induces high voltage spikes across the active switch), and current stress in switching device. A solution for this is to replace the boost input inductor by a coupled- inductor switching cell formed by a transistor. The voltage stress on the transistor was clamped by the output voltage. The rectifier diode should also withstand the output voltage. In order to even further reduce the current stresses on the switches, a new approach is considered, where a current limiting inductor connecting in the series with the secondary coil of the coupled inductor. Two diodes and a capacitor are added .The new converter features a high conversion ratio, high gain combined with a small voltage stress on the switches. It keeps the softswitching operation of both active and passive switches, and the alleviation of the recovery problem of the diodes.

The LC filter used to reduce ripple in the output voltage. To maintain output voltage constant and control the gate signal, PI controller is used and the output voltage feed back to the input. 


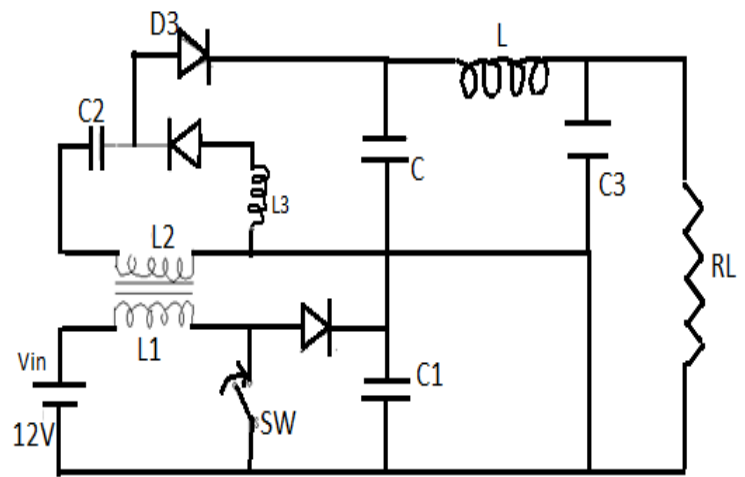

Fig 1 Proposed dc-dc converter circuit

\section{PWM GENRATION FOR GATE SIGNAL}

The duty cycle of Vgs (gate source voltage) is what allows a boost converter to function. As D increases, the gain also increases. In order to create a duty cycle, a PWM is required. There are several methods of creating a PWM. Here a triangle waveform is one wave that can be used to create a PWM. The operation is similar to the digital signal transmission using PWM signals. The DC input level voltage is compared to the current voltage of the triangular waveform as shown below:

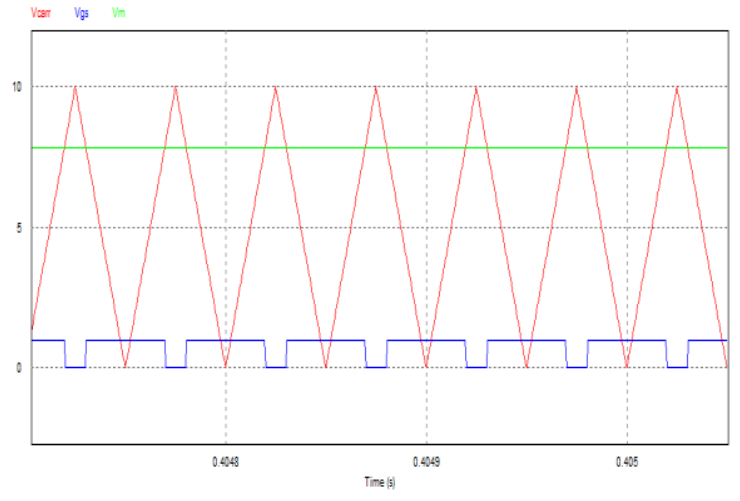

Fig 2: Gate signal (PWM)

The green waveforms are the triangular signals. The green line is the DC voltage level. Finally, the blue pulses are the output PWM. You can see how these pulses changes the duty cycle as the DC input level changes. Either a saw tooth or a triangle wave would work to create a PWM needed for the boost converter, but the triangle is an easier shape to create and the Triangle has a few distinct advantages over the saw tooth. "An intrinsic advantage of modulation using a triangle carrier wave is that the odd harmonic sideband components around odd multiples of the carrier fundamental and even harmonic sideband components around even multiples of the carrier fundamental are eliminated.” [13]
In close loop circuit the voltage regulation done by PI controller. The feedback loop is shown in the following diagram.

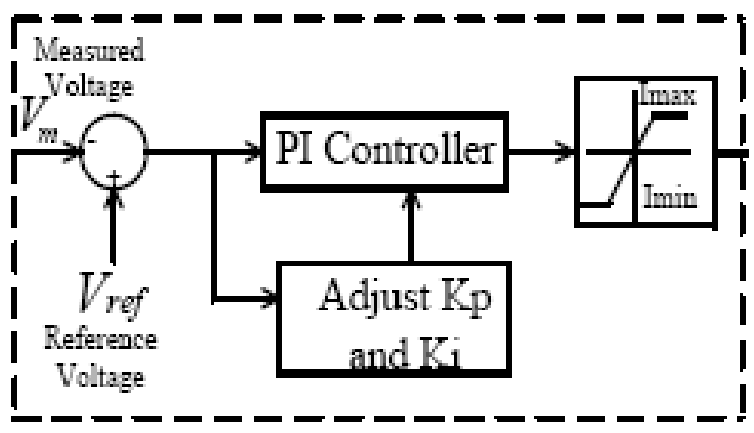

Fig 3: Voltage regulator block (Feedback loop)

\section{PI CONTROLLER}

A PI Controller (proportional-integral controller) is a special case of the PID controller in which the derivative (D) of the error is not used.

The controller output is given by

$$
K_{P} \Delta+K_{I} \int \Delta d t
$$

Where is the error or deviation of actual measured value $(\boldsymbol{P V})$ from the set point $(\boldsymbol{S P})$.

$$
\Delta=S P-P V
$$

A PI controller can be modeled easily in software such as Simulink using Laplace operators:

$$
C=\frac{G(1+\tau S)}{\tau S}
$$

Where

$G=K_{P}=$ proportional gain

$G / \tau=K_{I}=$ integral gain

Setting a value for is often a tradeoff between decreasing overshoot and increasing settling time. The lack of derivative action may make the system more stable in the steady state in the case of noisy data. This is because derivative action is more sensitive to higher-frequency terms in the inputs. In our circuit we considered $\mathrm{Kp}=.01 \tau=.001$ so $\mathrm{Ki}=.01 / .001=10$.

\subsection{Design Analysis}

The functions of main components of high gain DC-DC boost converter power stage are discussed and the individual values are determined to meet the project specification. The conduction mode of power stage is determined by input 
voltage, output voltage, output current and value of inductor. The input voltage, output voltage, load current are defined by project specification.

In project specification the input voltage $12 \mathrm{~V}$ generates the output voltage of $360 \mathrm{~V}$ with output current of $1 \mathrm{Amp}$. The calculation for output current is shown below, given the requirement for $360 \mathrm{~V}$ output voltage and $360 \mathrm{~W}$ output power. The power equation is:

$$
\mathrm{P}=\mathrm{V} \times \mathrm{I}
$$

The calculation of output current requires to supplying $360 \mathrm{~W}$ power to the load.

$$
\text { Iout }=\frac{\text { Pout }}{\text { Vout }}=\frac{360 \mathrm{~W}}{360 \mathrm{~V}}=1 \mathrm{Amp}
$$

The load resistor is calculated by ohm's low:

$$
\begin{gathered}
V=I \times R \\
\text { Rout }=\frac{\text { Vout }}{\text { Iout }}=\frac{360 \mathrm{~V}}{1 \mathrm{Amp}}=360 \Omega
\end{gathered}
$$

The turn ratio of coupling inductor is:

$$
\begin{gathered}
\sqrt{\frac{L 2}{L 1}}=\frac{V 2}{V 1}=\frac{N 2}{N 1} \\
\frac{N 2}{N 1}=6
\end{gathered}
$$

Time period during switch is $\mathrm{ON}$ condition i.e.

$$
T_{O N}=\frac{60}{60+12} \times 50 \mu s \cong 40 \mu s
$$

Time period during switch is OFF condition i.e.

$$
\begin{gathered}
T_{O F F}=T-T_{O N} \\
T_{O F F}=50 \mu s-40 \mu s \\
T_{O F F}=10 \mu s
\end{gathered}
$$

Duty cycle (D):

$$
\begin{aligned}
D=\frac{\text { Ton }}{\text { Ton }+ \text { Toff }} & =\frac{\text { Ton }}{T}=\frac{40 \mu}{50 \mu}=0.8 \\
D & =0.8
\end{aligned}
$$

The value of inductor L1 is calculates as follow:

$$
\begin{gathered}
L 1 \frac{d I_{L 1}}{d t}=V s \\
L 1=\frac{V s d t}{d I_{L 1}} \\
L 1=\frac{12 \times 40 \mu}{30} \\
L 1=16 \mu \mathrm{H}
\end{gathered}
$$

The value of inductor L2 is:

$$
\sqrt{\frac{L 2}{L 1}}=\frac{N 2}{N 1}=6
$$

$$
\begin{gathered}
\sqrt{\frac{L 2}{16}}=6 \\
L 2=16 \mu H \times(6)^{2}=576 \mu H
\end{gathered}
$$

Considering coupling coefficient $\mathrm{K}=0.95$,

The mutual inductance (M) between two coupling inductors is:

$$
\begin{gathered}
K=\frac{M}{\sqrt{L 1 \times L 2}} \\
M=0.99 \sqrt{16 \times 576} \\
M=95.04 \mu H
\end{gathered}
$$

\section{Specification:}

\begin{tabular}{|l|l|}
\hline Parameters & Value \\
\hline Input voltage or battery voltage & $12 \mathrm{~V}$ \\
\hline Output voltage & $360 \mathrm{~V}$ \\
\hline Out put power & $360 \mathrm{~W}$ \\
\hline Output current & $1 \mathrm{Amp}$ \\
\hline Operating frequency $\mathrm{F}$ & $20 \mathrm{KHz}$ \\
\hline Time period i.e. $\mathrm{T}=1 / \mathrm{F}$ & $1 / 20 \mathrm{KHz}=50 \mu \mathrm{s}$ \\
\hline
\end{tabular}




\section{SIMULATION RESULTS}

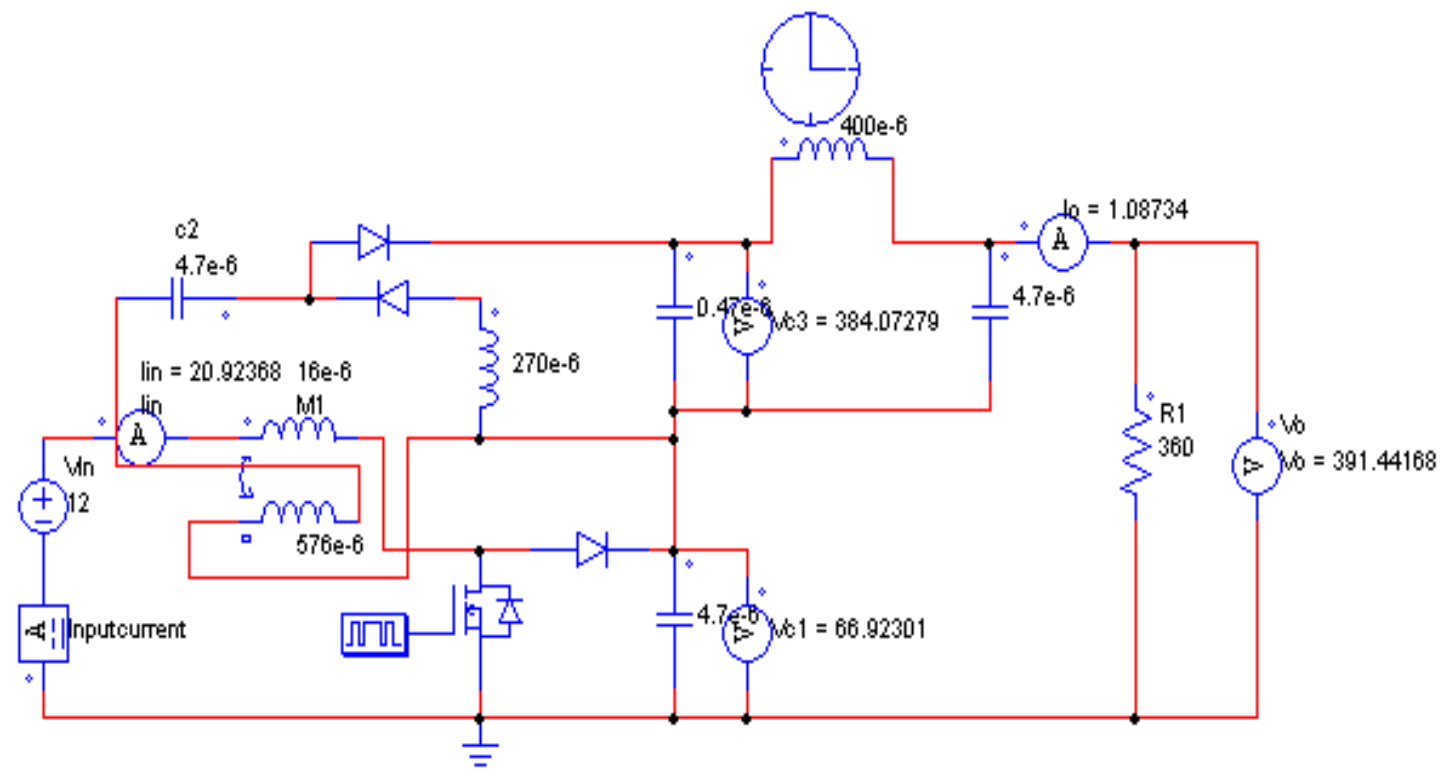

Fig 4: Simulation diagram of circuit (open loop)

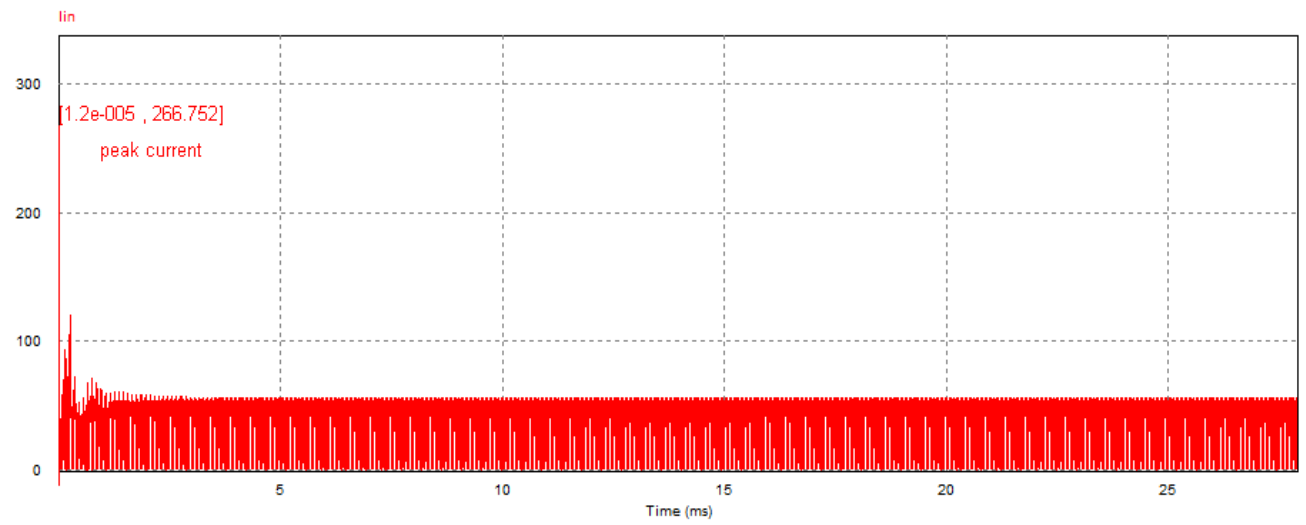

Waveform: Peak current without current limiting inductor L3

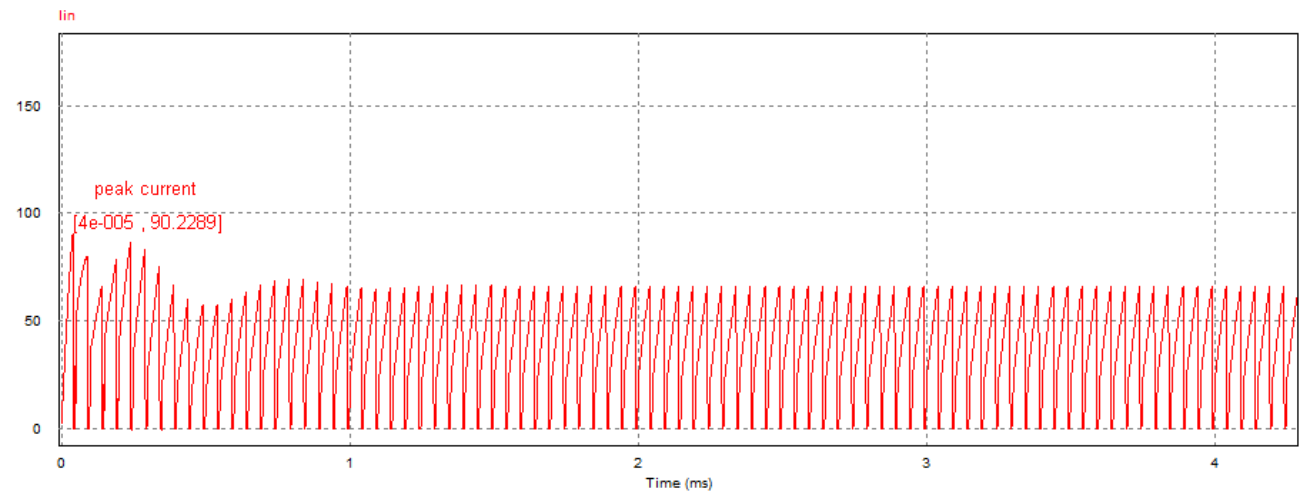

Waveform: Peak current with current limiting inductor $(\mathrm{L} 3=270 \mu \mathrm{H})$ 


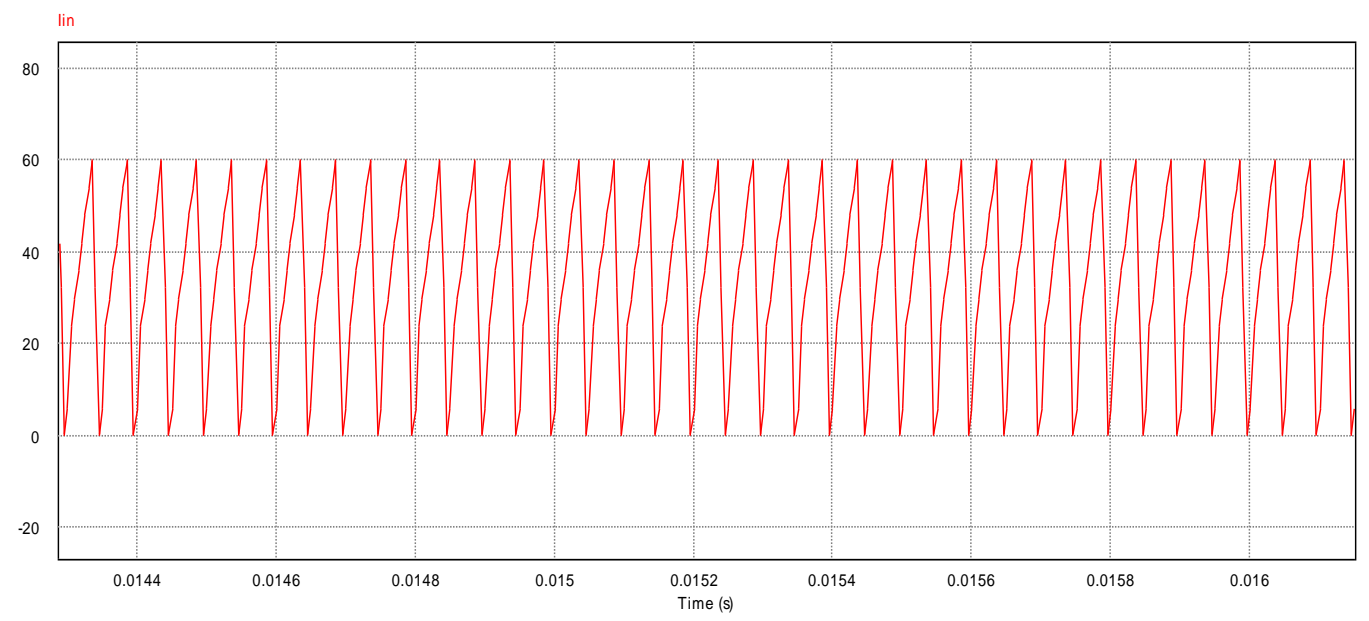

Waveform: Inductor current (IL1)

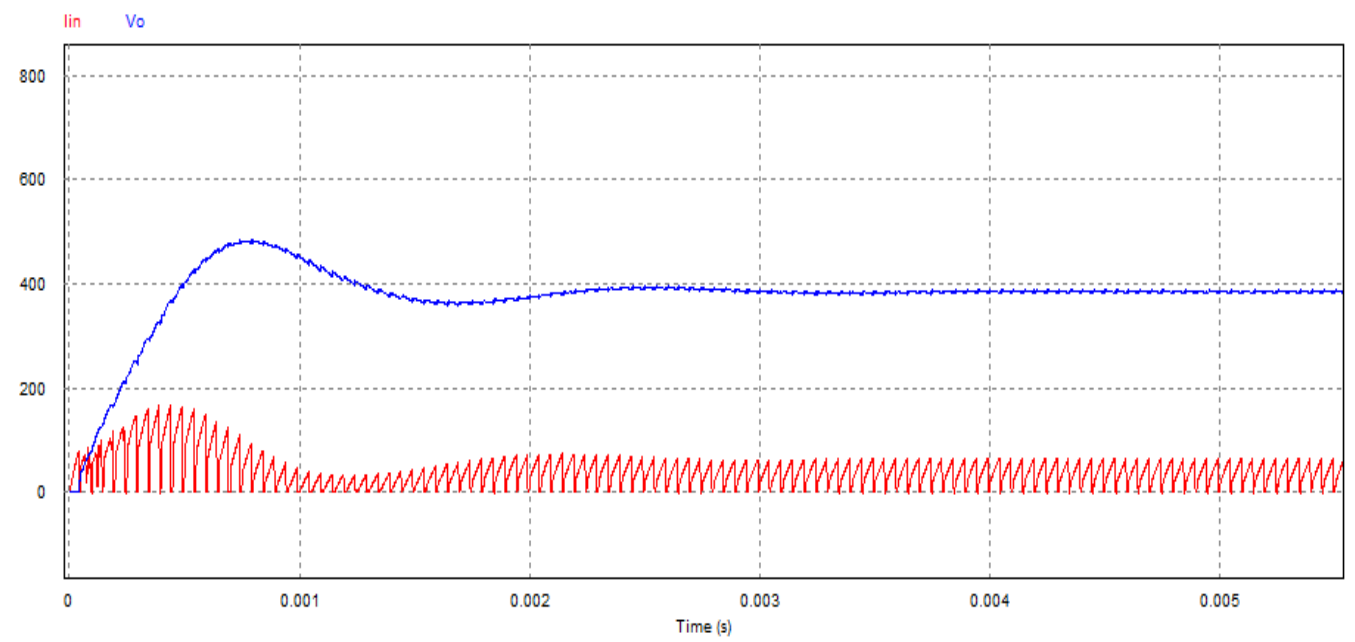

Waveform: The output voltage (Vo) and inductor current (IL1)

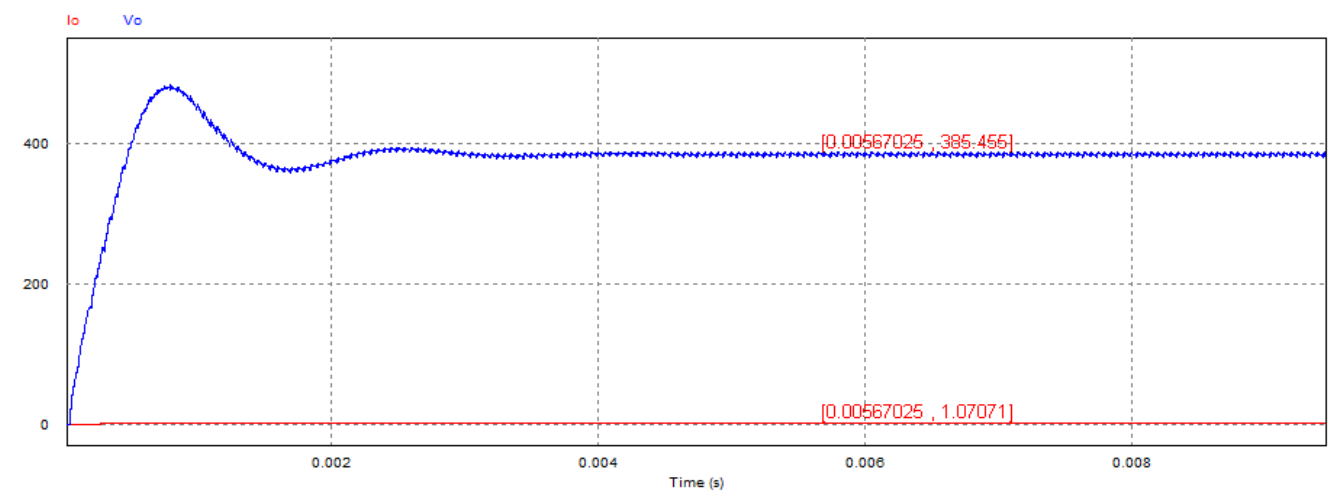

Waveform: output voltage (Vo ) and output current (Io) 
In this circuit my main aim is to stabilized the output voltage with better efficiency, remove the offset voltage and maintain the limit of switching current.

Apart this simplified the controlling action. According the limit of switching current we can able to select the switching device and diode. The PI controller is used to stabilize the output of the circuit. The proportional gain $\mathrm{Kp}=0.01$ and integral gain $\mathrm{Ki}=10$ and time constant $\tau=$ $0.001 \mathrm{~s}$ or $1 \mathrm{~ms}$. The simulation diagram of close loop circuit is shown below.

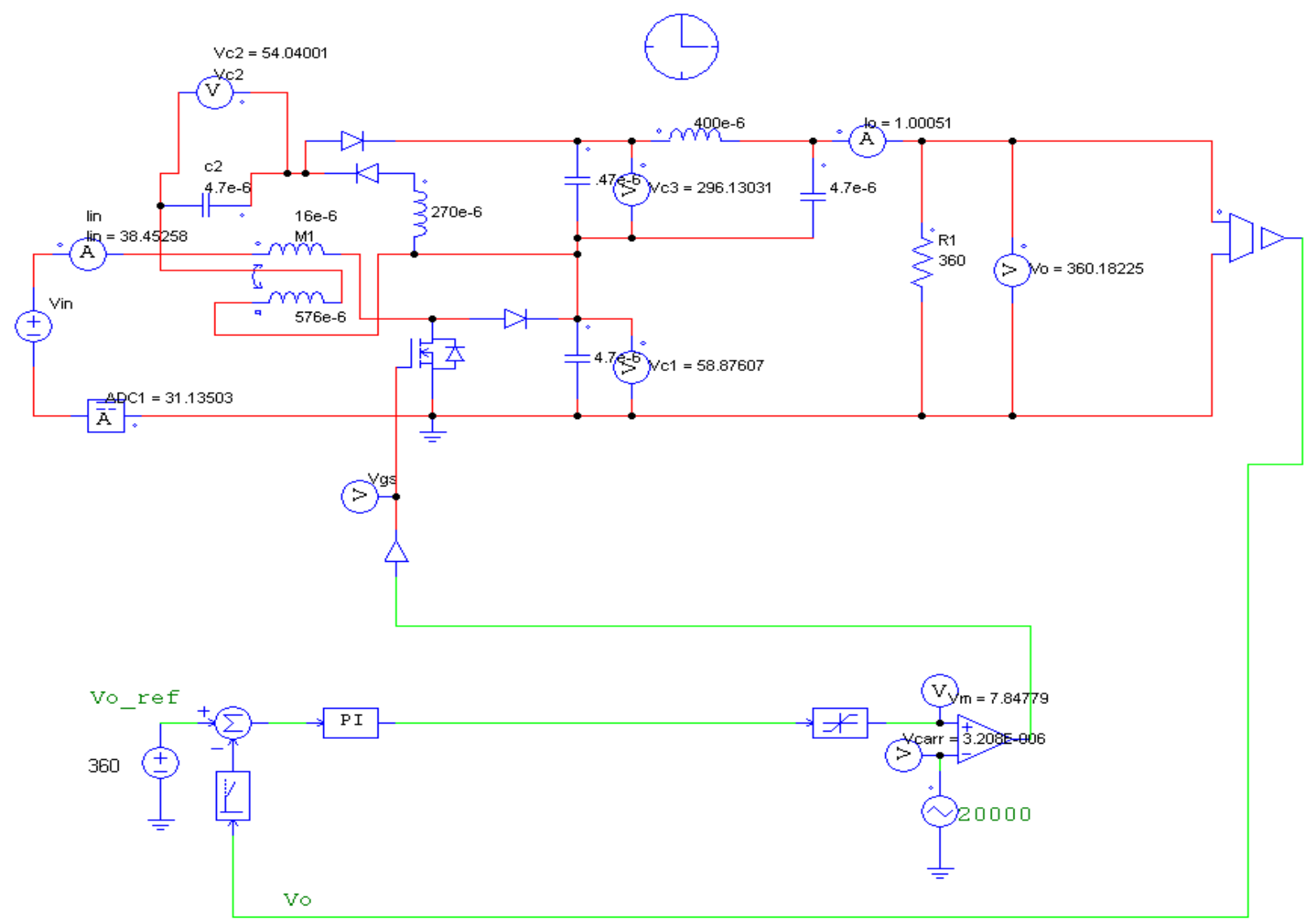

Fig 5: simulation diagram of circuit with feedback (close loop)

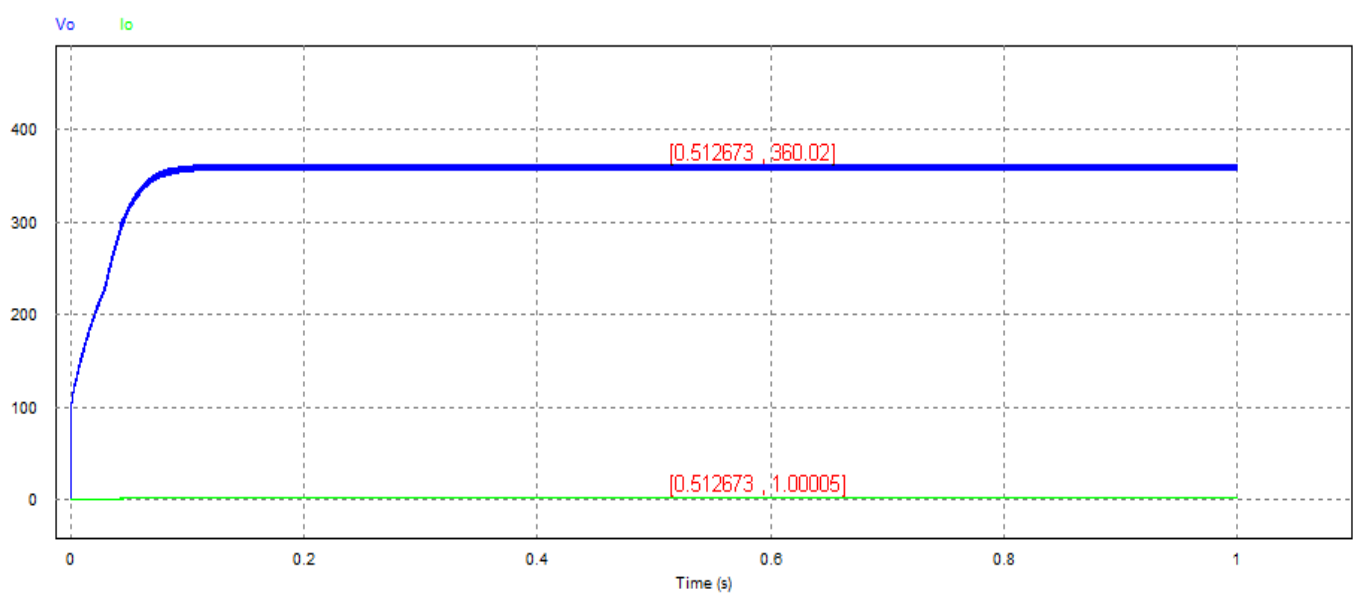

Waveform: output voltage (Vo) and output current (Io) 


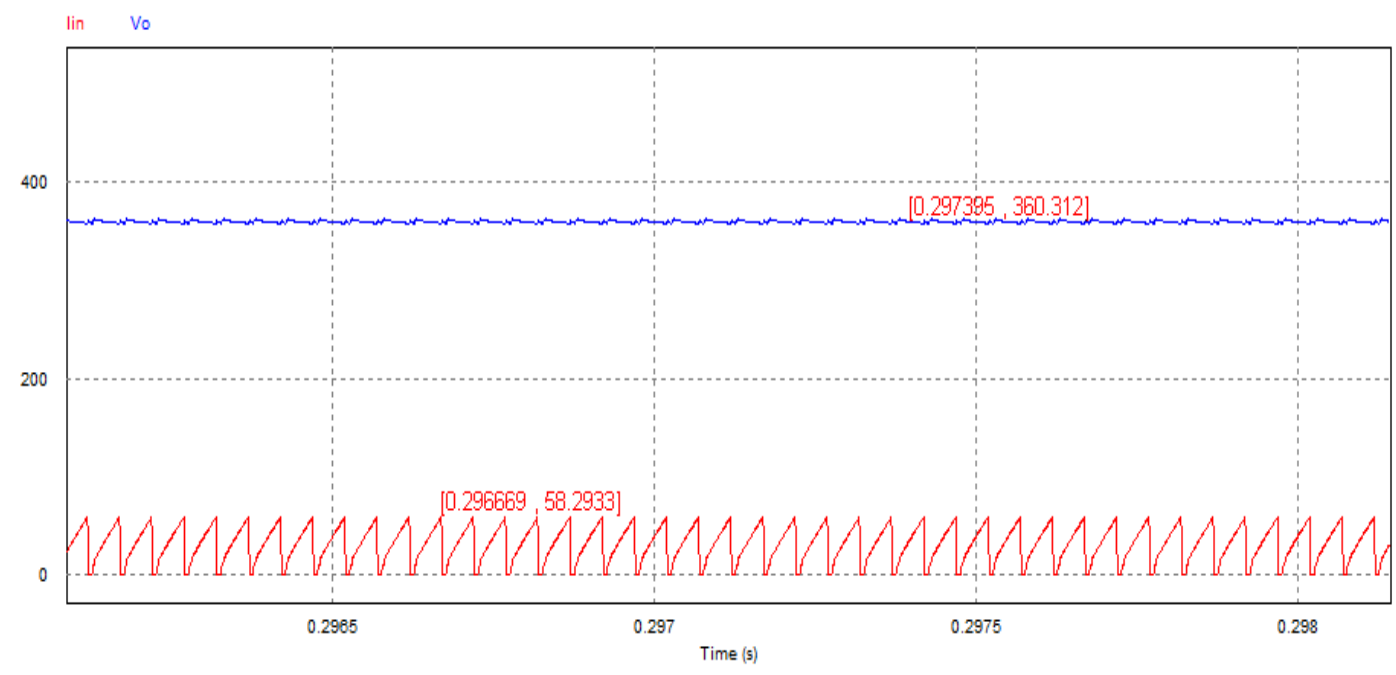

Waveform: output voltage(Vo) and inductor current (IL1)

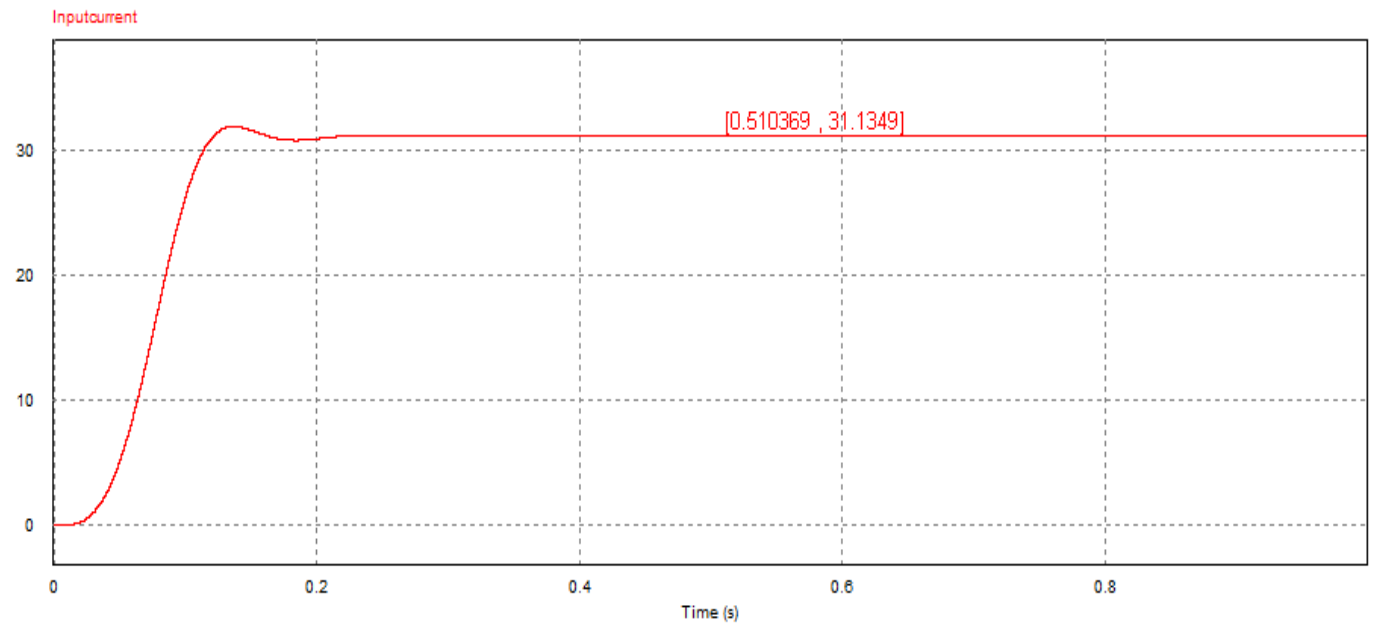

Waveform: Input current at full load condition

\section{EFFICIENCY TESTING}

The following efficiency testing was conducted in a closed loop configuration. The efficiency was calculated by the total power out divided by total power into the circuit.

Calculate the efficiency at full load condition by calculate the input power and output power.

$$
\text { Efficiency in percentage }=\frac{\text { Output power }}{\text { Input power }} \times 100
$$

At full load the output power $=V_{o} *$ Io

$$
\begin{gathered}
\text { Po }=360.3 * 1=360.3 \mathrm{~W} \\
\text { Pin }=\text { Vin } * \text { Iin }
\end{gathered}
$$

$$
\begin{gathered}
\text { Pin }=12 * 31.1=373.2 \mathrm{~W} \\
\text { Efficiency }=\frac{360.3}{373.3} \times 100=96.5 \%
\end{gathered}
$$

So we get better efficiency at full load condition that is $96.5 \%$ with control of switching peak current.

\section{CONCLUSIONS}

The boost converter is capable of operating at $20 \mathrm{KHz}$. The boost converter achieves a constant $360 \mathrm{~V}$ output when it is experiences at full load i.e. $360 \Omega$ and has voltage inputs of $12 \mathrm{~V}$. Furthermore, the boost converter minimized the switching peak current from 266A to $90 \mathrm{~A}$ by using current limiting inductor, alleviated the reverse recovery problem and achieve high step up voltage gain with duty cycle ratio of 0.8 . 
Because of the arrangement even if the control fail the fault peak current will never exceed 90Amp enhance the device of 100Amp also successes. As a whole, the boost converter achieved an efficiency above $90 \%$ with high voltage gain at an operating frequency of $20 \mathrm{kHz}$.

\section{REFERENCES}

[1] A. Freitas, F. Antun, E. Mineiro, A. Lima, A. Gadelha and F. Gualter "DC-DC high gain converter applied to renewable energy with new proposed to MPPT search", International Conference On Renewable Energies And Power Quality (ICREPQ'12) Santiago De Compostela (SPAIN),28 ${ }^{\text {th }}$ TO 30 ${ }^{\text {th }}$ March, 2012.

[2] A. Tomaszuk and A. Krupa "High Efficiency High Step Up DC-DC Converter" Bulletin of The Polish Academy Of Sciences Technical Sciences, Vol. 59, No. 4, 2011.

[3] Omar Hegazy, Student Member, IEEE, Joeri Van Mierlo and Philippe Lataire" Analysis, Control And Comparison Of Dc To Dc Boost Converter Topologies For Fuel Cell Hybrid Electric Vehicle Application" Vrije Universiteit Brussel (VUB) Pleinlaan 2, B-1050 Brussels, Belgium.

[4] B. Axelrod, Y. Berkovich, S. Tapuchi*, A. Ioinovici," Improved Circuit Of The Switching Coupled Inductor Cell For Dc To Dc Converters With Very Large Conversion Ratio" Holon Institute Of Technology 52 Golomb St., Holon 58102, Israel.

[5] S. M. El-Ghanam1, W. Abdel Basit1*, M. Ismail1, S. A. Kamh1, H. A. Ashry2 and F. A. S. Soliman "Enhanced switching characteristics of DC-DC boost converter systems" Physical Sciences Research International Vol. 1(2), pp. 25-31, May 2013.

[6] Qun Zhao "Performance Improvement of Power Conversion by Utilizing Coupled Inductors" Doctor of Philosophy In Electrical Engineering February 03, 2003 Blacksburg, Virginia.

[7] Shamim Choudhury "Digital Control Design and Implementation of a DSP Based High-Frequency DCDC Switching Power Converter" Texas Instruments Inc. 12203 Southwest Freeway, MS 728 Stafford, Texas 77477, USA.

[8] Priscila Facco de Melo, Roger Gules, Eduardo Felix Romaneli, Rafael Christiano Annunziato "A SoftSwitching Universal-Input Voltage Hpf Rectifier Implemented With A Modified Sepic Converter" Federal University of Technology - Paraná - UTFPR Curitiba - PR - Brazil - 80230-901 2009 IEEE.

[9] Theodore Soong, Peter Lehn “A Transformerless High Boost DC-DC Converter for use in Medium / High Voltage Applications" University of Toronto, 10 King's College Rd., Toronto, 2012 IEEE.

[10] Pravin D. Patel, Miteshkumar N.Priyadrshi, Vinod P. Patel "Design and Implementation of Isolated High Power DC/DC Boost Converter Using DSP" Third
International Conference on Industrial and Information Systems, Kharagpur, INDIA December 8 -10, 2008 IEEE.

[11] Felinto S. F. Silva1, Antônio A. A Freitas2, Sérgio Daher2, Saulo C. Ximenes2, Sarah K. A. Sousa2,Edilson M. S. Jr.3 , Fernando L. M. Antunes2, Cícero M. T. Cruz2." high gain dc-dc boost converter with a coupling inductor" 978-1-4244-33704/09/\$25.00 @ 2009 IEEE 486.

[12] Falah Al Hassan*, Vladimir L. Lanin "Lossless DCDC Boost Converter With High Voltage Gain For PV Technology" Asian Transactions on Engineering (ATE ISSN: 2221 - 4267) Volume 02 Issue 04 September 2012 IEEE.

[13] Rus, D. C., N. S. Preda, I. I. Incze, Maria Imecs, and Cs Szab. "Comparative Analysis of PWM Techniques:." IEEExplore (2010). Print. 